\title{
Primary health care for children - evidence for prevention
}

\author{
Susanne Carai ${ }^{1,2^{*}}$ and Martin W. Weber ${ }^{1}$
}

Primary health care is the cornerstone of universal health coverage and guarantor of quality comprehensive health care for all, including children [1]. Views on what comprehensive primary health care entails and what health services can and should deliver at the primary health care level for children and adolescents differ. Different health systems offer a range of curative and preventive interventions for children and adolescents. Some of those interventions are evidence-based with proven benefits. Others are common practices based on tradition, expert opinion, or common sense and there is no felt need for justifying their effectiveness or benefit. Some interventions however may not only be without benefit for the child but harmful $[2,3]$.

Against this backdrop, the WHO Pocket Book on Primary Health Care for Children and Adolescents (see Fig. 1 below) defines evidence-based standards of health care for a child or adolescent according to which every child attending primary health care services across the European Region should be cared for. During the development process of the Pocket Book, it became apparent that recommendations and practices for preventive interventions for infants and children are particularly controversial and the book's editorial group and members of the European Confederation for Primary Care Paediatricians (ECPCP) realised the need for collating existing evidence for recommendations and practices for disease prevention for infants, children and adolescents.

This supplement summarises and reviews the available evidence for selected preventive interventions to inform key chapters of the Pocket Book and thereby helps to close the practice gap for prevention. In a series of articles, Sophie Jullien and colleagues first provide the background, describe the methods in detail, and present the supplement's main findings [4]. The author then

\footnotetext{
* Correspondence: sc@dischi.de

${ }^{1} \mathrm{WHO}$, Regional office for Europe, Copenhagen, Denmark

${ }^{2}$ Witten/Herdecke University, Witten, Germany
}

critically reviews and summarises the strengths of the recommendations and quality of evidence for ten preventive interventions based on major documents of international paediatric societies and institutions, mostly from Europe [5-14].

The Pocket Book aims to help deliver on the promise of primary health care: its focus on evidence-based practices and prevention should counteract inappropriate medicalisation of health services (i.e. preferring invasive or active treatment over conservative or watchful management, intravenous treatment over oral rehydration therapy and multiple drugs over just one) and prevent unnecessary treatment and hospitalisation. Its success, however, will also require a critical review of healthsystem financing.

As of today, health spending overwhelmingly goes towards curative care, not prevention: Europe's governments spend only $3 \%$ of the total health expenditure (THE) on health promotion and disease prevention [15]. Funding needs to be made available to enable the provision of evidence-based treatment and prevention services for children and adolescents. These services need to be included in state-guaranteed benefits packages or covered under health insurance schemes to be made available for children and adolescents without cost to them at the point of care.

Attaining the sustainable development goals (SDGs) requires a substantial shift in thinking about child and adolescent health, according to the global review of the implementation of the UNICEF/WHO Strategy of the Integrated Management of Childhood Illness (IMCI) to reduce childhood mortality and improve quality of care for children [16]. The focus moves from the survival of children under 5 years old to a holistic view of child and adolescent health and attention shifts to health promotion, disease prevention, early risk factor management and monitoring of chronic conditions 


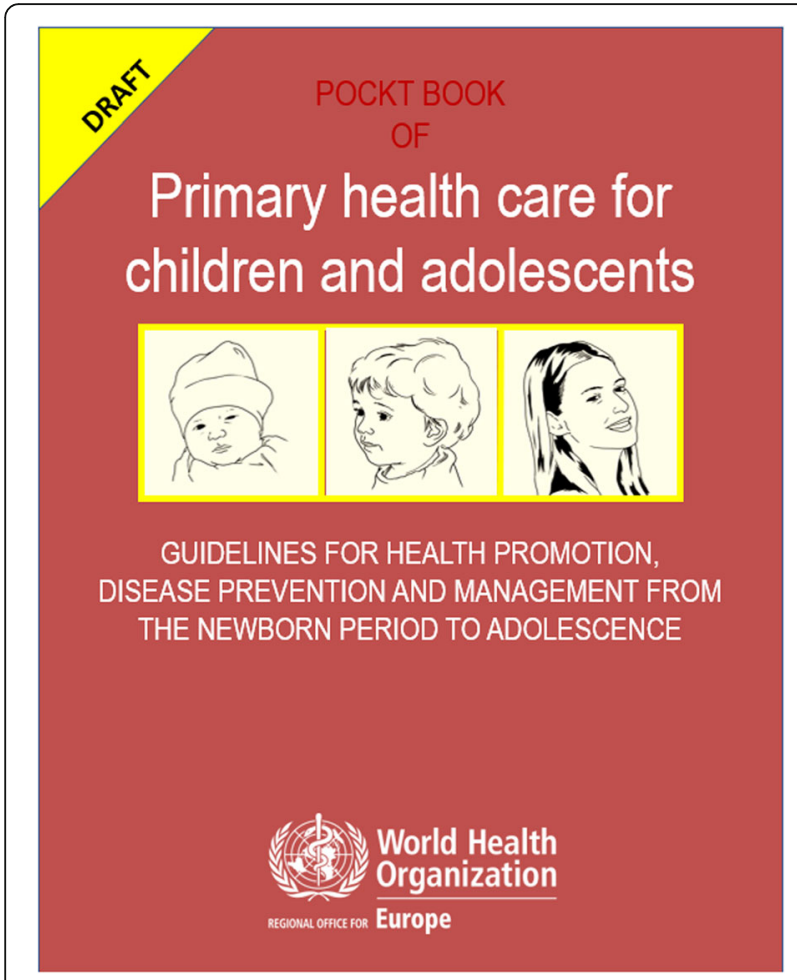

Fig. 1 The draft WHO Pocket Book of Primary Health Care for Children and Adolescents, expected publication date end 2021

[17]. The summaries of evidence for preventive interventions for children published in this supplement are an important step in this direction and providing comprehensive evidence-based primary health care for children and adolescents.

\section{About the supplement}

This article has been published as part of BMC Pediatrics Volume 21, Supplement 1 2021: Defined preventive interventions for children under five years of age: evidence summaries for primary health care in the WHO European region. The full contents of the supplement are available at https://bmcpediatrics.biomedcentral.com/articles/supplements/volume-21supplement-1.

\section{Authors'contributions}

Both authors developed the idea for the manuscript. SC wrote the draft manuscript. MW provided critical appraisal of the manuscript. SCmade subsequent revisions and both authors read and approved the final manuscript. The authors gratefully acknowledge support of the editorial group of the WHO Pocket Book of Primary Health Care for Children and Adolescents in Europe, particularly Julia Mutevelli. The author(s) read and approved the final manuscript.

\section{Funding}

The development of the Pocket Book and related activities were partially funded by the Federal Ministry of Health of Germany and through a grant of the Russian Government.

\section{Declarations}

Ethics approval and consent to participate Ethics approval was not required.

\section{Availability of data and materials}

Not applicable

\section{Competing interests}

The authors declare that they have no competing interests. MW is a staff member of the World Health Organization. The authors alone are responsible for the opinions expressed in this publication and they do not necessarily reflect the policies and positions of the World Health Organization. Funding for the editorial: Not applicable The development of the Pocket Book and related activities were partially funded by the Federal Ministry of Health of Germany and through a grant of the Russian Government.

Published: 8 September 2021

\section{References}

1. World Health Organization \& United Nations Children's Fund (UNICEF). (2018). A vision for primary health care in the 21st century: towards universal health coverage and the Sustainable Development Goals. World Health Organization. https://apps.who.int/iris/handle/10665/328065. License: CC BY-NC-SA 3.0 IGO

2. Carai S, Kuttumuratova A, Boderscova L, Khachatryan H, Lejnev I, Monolbaev K, Uka S, Weber M. Review of Integrated Management of Childhood IIIness (IMCI) in 16 countries in Central Asia and Europe: implications for primary healthcare in the era of universal health coverage. Arch Dis Child. 2019 104(12):1143-1149. https://doi.org/10.1136/archdischild-2019-317072. Epub 2019 Sep 26. PMID: 31558445; PMCID: PMC6900244.

3. World Health Organization. Regional Office for Europe. (2020). Assessments of sexual, reproductive, maternal, newborn, child and adolescent health in the context of universal health coverage in six countries in the WHO European Region: a synthesis of findings from the country reports. https://a pps.who.int/iris/handle/10665/331392. License: CC BY-NC-SA 3.0 IGO

4. Jullien $S$, Huss G, Weigel, R. Supporting recommendations for childhood preventive interventions for primary health care: elaboration of evidence synthesis and lessons learnt. BMC Pediatrics. 2021. https://doi.org/10.1186/ s12887-021-02638-8.

5. Jullien S. Vitamin D prophylaxis in infancy. BMC Pediatrics. 2021. https://doi. org/10.1186/s12887-021-02776-z.

6. Jullien S. Vitamin K prophylaxis in newborns. BMC Pediatrics. 2021. https:// doi.org/10.1186/s12887-021-02701-4.

7. Jullien S. Prophylaxis of caries with fluoride for children under five years. BMC Pediatrics. 2021. https://doi.org/10.1186/s12887-021-02702-3.

8. Jullien S. Sudden infant death syndrome prevention. BMC Pediatrics. 2021. https://doi.org/10.1186/s12887-021-02536-z.

9. Jullien S. Prevention of unintentional injuries in children under five years. BMC Pediatrics. 2021. https://doi.org/10.1186/s12887-021-02517-2.

10. Jullien S. Vision screening in newborns and early childhood. BMC Pediatrics. 2021. https://doi.org/10.1186/s12887-021-02606-2.

11. Jullien S. Newborn screening for critical congenital heart defects. BMC Pediatrics. 2021. https://doi.org/10.1186/s12887-021-02520-7.

12. Jullien S. Screening of iron deficiency anaemia in early childhood. BMC Pediatrics. 2021. https://doi.org/10.1186/s12887-021-02725-w.

13. Jullien S. Screening for autistic spectrum disorder in early childhood. BMC Pediatrics. 2021. https://doi.org/10.1186/s12887-021-02700-5.

14. Jullien S. Screening for language and speech delay in children under five years. BMC Pediatrics. 2021. (in press).

15. European Commission Eurostat https://ec.europa.eu/eurostat/web/productseurostat-news/-/ddn-20210118-1. https://ec.europa.eu/eurostat/databrowser/ view/HLTH_SHA11_HC_custom_423640/bookmark/table?lang=en\&bookma $r k l d=f 1817640-9 f 59-4759-8 f 4 d-09 a a 5721370$. [Accessed 28.04.2021].

16. Costello AM and Dalglish SL on behalf of the Strategic Review Study Team. "Towards a Grand Convergence for child survival and health: A strategic review of options for the future building on lessons learned from IMNCI." Geneva: WHO, 2016.

17. Simon J L, Daelmans B, Boschi-Pinto C, Aboubaker S, Were W. Child health guidelines in the era of sustainable development goals BMJ 2018; 362:bmj. k3151. https://doi.org/10.1136/bmj.k3151

\section{Publisher's Note}

Springer Nature remains neutral with regard to jurisdictional claims in published maps and institutional affiliations. 